Old Dominion University

ODU Digital Commons

Nursing Faculty Publications

Nursing

2011

\title{
Telehealth Stroke Education For Rural Elderly Virginians
}

Patricia A. Schweickert

Carolyn M. Rutledge

Old Dominion University, crutledg@odu.edu

David C. Cattell-Gordon

Nina J. Solenski

Mary E. Jensen

See next page for additional authors

Follow this and additional works at: https://digitalcommons.odu.edu/nursing_fac_pubs

Part of the Educational Technology Commons, and the Public Health and Community Nursing Commons

\section{Original Publication Citation}

Schweickert, P. A., Rutledge, C. M., Cattell-Gordon, D. C., Solenski, N. J., Jensen, M. E., Branson, S., \& Gaughen, J. R. (2011). Telehealth stroke education for rural elderly Virginians. Telemedicine and e-Health, 17(10), 784-788. doi:10.1089/tmj.2011.0080

This Article is brought to you for free and open access by the Nursing at ODU Digital Commons. It has been accepted for inclusion in Nursing Faculty Publications by an authorized administrator of ODU Digital Commons. For more information, please contact digitalcommons@odu.edu. 


\section{Authors}

Patricia A. Schweickert, Carolyn M. Rutledge, David C. Cattell-Gordon, Nina J. Solenski, Mary E. Jensen, Sheila Branson, and John R. Gaughen 


\section{Telehealth Stroke Education for Rural Elderly Virginians}

\author{
Patricia A. Schweickert, D.N.P., F.N.P.-B.C., ${ }^{1}$ \\ Carolyn M. Rutledge, Ph.D., F.N.P.-B.C., ${ }^{2}$ \\ David C. Cattell-Gordon, M.Div., M.S.W., ${ }^{1}$ Nina J. Solenski, M.D., ${ }^{1}$ \\ Mary E. Jensen, M.D., ${ }^{1}$ Sheila Branson, M.S.N., F.N.P., ${ }^{3}$ \\ and John R. Gaughen, M.D. ${ }^{1}$ \\ ${ }^{1}$ University of Virginia, Charlottesville, Virginia. \\ ${ }^{2}$ Graduate School of Nursing, Old Dominion University, \\ Norfolk, Virginia. \\ ${ }^{3}$ MEOC PACE, Big Stone Gap, Virginia.
}

\section{Abstract}

Objective: Stroke is a prevalent condition found in elderly, rural populations. However, stroke education, which can be effective in addressing the risks, is often difficult to provide in these remote regions. The objective of this study is to evaluate the effectiveness of delivering stroke education to elderly individuals through telehealth versus inperson stroke prevention education methods. Materials and Methods: A quasi-experimental nonequivalent control group design was used in this study. A convenience sample of 11 elderly adults (36\% men, 64\% women) with a mean age of 70 was selected from an Appalachian Program for All Inclusive Care for the Elderly (day care) facility. Subjects completed preintervention surveys, received a 20-min group inperson or telehealth delivered education session, and then completed the postintervention surveys. Results: Satisfaction with delivery method and post-education knowledge was equivalent between the two groups. Knowledge increased in both groups after the educational programs. Likelihood of reducing risk factors showed no differences pre-posttest. However, there were significant improvements in the pre-post likelihood scores of the telehealth group in contrast to the in-person group. Conclusions: This project provided a rural, high-risk population access to telehealth stroke education, thus enabling these individuals to receive education at a distance from experts in the field. The telehealth program was found to be equivalent to in-person stroke education in regards to satisfaction, knowledge, and likelihood of making changes to decrease vascular risk factors. The study demonstrated feasibility in providing effective stroke education through telehealth, thus suggesting an often overlooked route for providing patient education at a distance.

Key words: telehealth, teleradiology, telemedicine

\section{Introduction}

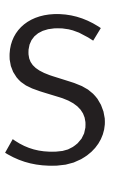

troke is a serious global public health issue. ${ }^{1}$ It is the third leading cause of death in the United States and the leading cause of long-term disability. The predominance of vascular risk factors leads to this high proportion of stroke in our society. ${ }^{2}$ Stroke often impacts the elderly in rural areas resulting in increased morbidity and mortality. ${ }^{3,4}$ Limited access to expert stroke care contributes to the higher stroke-related disability and poorer outcomes in rural populations. ${ }^{5}$ Efforts to decrease the incidence of stroke include stroke education, as stroke education has been shown to reduce vascular risk factors. ${ }^{6-12}$ Stroke education via telehealth can provide rural communities access to preventative education and to experts that are often missing in the rural communities. There is a need to determine whether telehealth stroke education is feasible, whether it is comparable to in-person education in regards to satisfaction, and whether it is effective in increasing knowledge of stroke.

The purpose of this project was to evaluate the effectiveness of telehealth education in comparison to the traditional in-person stroke prevention education. Specific emphasis was on comparing the two methods in regards to satisfaction, knowledge, and likelihood of making behavioral changes to reduce vascular risk factors.

\section{RATIONALE FOR STUDY}

The most important benefit of telemedicine is the improved access to care for patients who live in medically underserved areas where there are considerable barriers to care for disabilities such as in stroke. ${ }^{4}$ Traveling, often long distances, to facilities to receive specialty care is a hardship on rural stroke patients. ${ }^{13-16}$ Telehealth is a method to overcome such barriers to the delivery of care by providing ready access to distant providers through televised modalities.

Telehealth education has been shown to be satisfying and effective in studies with patients suffering from cardiovascular disease and diabetes. ${ }^{17-22}$ Winters and Winters, ${ }^{17}$ using a series of pilot studies, suggested that there was a high level of satisfaction with patient education activities via telehealth in cardiovascular disease. Telehealth diabetes education in the elderly and in rural communities was viewed positively by subjects with improvements in diabetes knowledge. ${ }^{20,21}$ A systematic review of telehealth and diabetes care revealed it to be beneficial and useful, showing success with group education. ${ }^{22}$

This stroke telehealth education project has a potentially wide scope of application in providing access to care for elderly, high-risk rural populations. It embraces healthcare goals of decreasing incidence of stroke by providing equitable access to care for vulnerable individuals and has importance to clinical practice by providing evidence on the usefulness of telehealth in stroke prevention education. $^{2,23-25}$ Stroke prevention education is needed in high-risk, rural, and underserved areas due to the great burden of stroke in these populations. The National Clinical Guidelines for Stroke recommend that stroke prevention education be provided to the very elderly to reduce the risk of stroke. ${ }^{26}$ Education to affect behavior change is paramount in the effort to reduce the incidence of stroke. ${ }^{10}$ 


\section{TELEHEALTH STROKE EDUCATION}

\section{Materials and Methods}

This study was conducted in the Appalachian region of Virginia, at a Program for All Inclusive Care for the Elderly (PACE) center. The telehealth education session was transmitted to PACE via high-speed videoconferencing from a central Virginia medical center. The project was approved for human subject's protection by the Institutional Review Board of the two state universities. Data collected included subjects' age, race, gender, education, stroke risk factors, knowledge of stroke, satisfaction with delivery method, and likelihood of taking actions to decrease risk of stroke.

This study utilized a quasi-experimental pretest-posttest control group design. Both groups completed the consent and pretest questionnaire packet. They then participated in a stroke education program. The comparison group received the stroke education in person, whereas the study group received the education through a telehealth platform. Following the session, both groups completed the posttest questionnaire packet.

Participants included were members of PACE who were 55-90 years of age and able to give informed consent, participate in a stroke education session, and complete the questionnaires. Subjects were chosen by convenience sampling according to the day they attended the clinic. A sample of 23 subjects was invited to participate (12 inperson/11 telehealth). Nineteen subjects agreed to the study (10 inperson/9 telehealth) and four refused. Five subjects in the in-person group were ill on the day of the educational session, two were ill on the day of the telehealth education session, and one dropped out due to a prior appointment. This resulted in five subjects in the in-person group and six subjects in the telehealth group.

\section{INTERVENTIONS}

The researcher presented a 20-min stroke prevention education session based on National Institute of Neurologic Disorders and Stroke-National Institute of Health (NINDS-NIH) stroke information. The education session began with an 8-min video and was followed by a discussion of stroke risk factors and prevention using PowerPoint slides. The content included stroke definitions, symptoms, risk factors, risk reduction, and actions to take if someone has a stroke or transient ischemic attack. The session was interactive with participants asking and answering questions.

The researcher presented the stroke education to the in-person comparison group during their day at the PACE center. The participants were assembled in the conference room at the center. Immediately after the session, the PACE nurse practitioner distributed the posttest questionnaires to each participant in the in-person group. Once completed, the PACE nurse practitioner collected posttests and questionnaires and placed them in a sealed envelope that was stored securely in a locked box by the researcher until the end of the study.

The following day, the researcher presented the telehealth education from over 300 miles away at the University of Virginia. The telehealth group gathered in the conference room for the researcher's same 20-min stroke prevention education session via a link from the Central Virginia Medical Center to the telehealth group. The telehealth stroke prevention education was transmitted via high-speed videoconferencing technology using computer screens, cameras, and software. The education session was identical in content and presentation to the program provided to the comparison group in person. Immediately after the program, the PACE nurse practitioner distributed the posttest questionnaire packet to each participant in the telehealth group and they were completed in identical fashion. Since the researcher was not on-site at the PACE center, this envelope was placed in a preaddressed Federal Express envelope and sent directly to the researcher where it was stored securely in a locked box with the remainder of the data.

\section{DATA COLLECTION TOOLS}

Stroke risk factors and demographic data were assessed using a researcher-designed questionnaire based on stroke risk factors identified by the American Stroke Association (ASA). ${ }^{27}$ Fifteen stroke risk factors were listed for the participants to respond to with yes or no answers in order to identify their risk factors. Likelihood of taking actions to decrease the risk of stroke was assessed by a researcherdesigned questionnaire based on ASA risk factors. Seven actions that were deemed as important by the ASA were listed on a five-point Likert scale with " 1 " being "not very likely" to " 5 " being "very likely" to take action. Pre- and posttest knowledge related to stroke symptoms and risk factors was assessed by an NINDS-NIH-designed quiz adapted for this study. This included 18 true or false items. The total number of correct answers was computed to indicate the participant's knowledge. Satisfaction with delivery method was assessed by a researcher-designed questionnaire. This questionnaire consisted of items related to the participant's ability to see, hear, and communicate with the presenter. It also addressed comfort with the format and overall satisfaction. Satisfaction was measured on a five-point Likert scale with " 1 " being "strongly disagree" to " 5 " being "strongly agree." All of the tools were assessed for face and content validity by an expert in tool development and experts in the field of telehealth and stroke.

\section{DATA ANALYSIS}

Sociodemographic and stroke risk factors were analyzed using frequency, percentages, sums, and means. Differences between the two groups were assessed using the Mann-Whitney U test due to the number of subjects and level of data. Within-group assessment was performed with the Wilcoxon t-test. Statistical analysis was performed with PASW Statistics GradPack 18.

\section{Results}

Demographic data are presented on the subjects who participated in the study for the groups as a whole and then for each group separately (Table 1). Both groups of participants were similar related to age, education, and race. Subjects were rural, elderly aged 64-76 who were mostly of Caucasian race with 8-9 years of education. Comparable rates of prior experience with telehealth between the telehealth and in-person group were present. Differences in gender were observed between groups as the telehealth group contained 


\begin{tabular}{|c|c|c|c|}
\hline & $\begin{array}{l}\text { BOTH } \\
\text { GROUPS }\end{array}$ & $\begin{array}{l}\text { IN-PERSON } \\
\text { (CONTROL) }\end{array}$ & $\begin{array}{c}\text { TELEHEALTH } \\
\text { (EXPERIMENTAL) }\end{array}$ \\
\hline \multicolumn{4}{|l|}{ Age $(n=11)$} \\
\hline Mean & 70 & 69 & 71 \\
\hline Range & $64-76$ & $65-76$ & $64-75$ \\
\hline \multicolumn{4}{|l|}{ Gender $(n=11)$} \\
\hline Male & $4(36 \%)$ & $0(0 \%)$ & $4(67 \%)$ \\
\hline Female & 7 (74\%) & $5(100 \%)$ & $2(33 \%)$ \\
\hline \multicolumn{4}{|l|}{ Ethnicity $(n=11)$} \\
\hline Caucasian & $8(73 \%)$ & $3(60 \%)$ & $5(83 \%)$ \\
\hline Other & $3(27 \%)$ & $2(40 \%)$ & $1(16.7 \%)$ \\
\hline \multicolumn{4}{|c|}{ Level of education $(n=11)$} \\
\hline Mean & 8.73 & 8 years & 9.5 years \\
\hline Range & $4-15$ years & $5-12$ years & $4-15$ years \\
\hline Elementary & $3(27.3 \%)$ & $1(20 \%)$ & $2(33 \%)$ \\
\hline Middle & $4(36.4 \%)$ & $3(60 \%)$ & $1(17 \%)$ \\
\hline High school grad & $2(18.2 \%)$ & $1(20 \%)$ & $1(17 \%)$ \\
\hline Some college & $2(18.2 \%)$ & $0(0 \%)$ & $2(33 \%)$ \\
\hline \multicolumn{4}{|c|}{ Prior telehealth experience $(n=11)$} \\
\hline Yes & $4(36 \%)$ & $2(40 \%)$ & $2(33 \%)$ \\
\hline No & $7(64 \%)$ & $3(60 \%)$ & $4(66 \%)$ \\
\hline \multicolumn{4}{|c|}{ Prior stroke education $(n=11)$} \\
\hline Yes & $6(54 \%)$ & $1(20 \%)$ & $5(83 \%)$ \\
\hline No & $5(46 \%)$ & $4(80 \%)$ & $1(17 \%)$ \\
\hline
\end{tabular}

Note: values are provided as $n(\%)$.

one-third men and the in-person group contained all women. The risk factors that were found to be the most prevalent (over $50 \%$ of the participants) included TIA, hypertension, heart disease, myocardial infarction, diabetes, and hyperlipidemia.

In order to assess whether there were significant differences between the telehealth and the in-person group in satisfaction with delivery methods, knowledge, and likelihood of making behavioral changes to decrease vascular risk factors, the Mann-Whitney U test was used (Table 2). There was no significant difference between groups in knowledge $(p \geq 0.05)$ or likelihood of making behavioral changes to reduce vascular risk factors $(p \geq 0.05)$ prior to the intervention. There was also no difference $(p \geq 0.05)$ between the telehealth group and the in-person group knowledge, in the likelihood of making changes to reduce vascular risk factors, or in satisfaction with the delivery method after the intervention. Thus, the telehealth and the in-person education programs were comparable related to impact

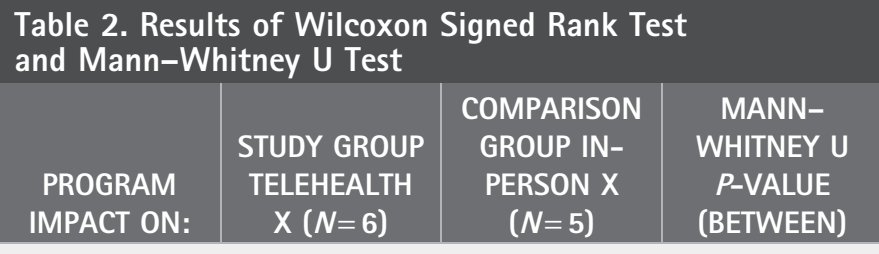

Knowledge of stroke and stroke risk factors

\begin{tabular}{l|l|l|l}
\hline Before & 11.3 & 12.8 & 0.220 \\
\hline After & 17.33 & 16.6 & 0.329 \\
\hline \multicolumn{5}{|l}{ Wilcoxon signed ranks } \\
\hline$p$ value (within) & 0.026 & 0.042 & \\
\hline
\end{tabular}

Pretest-posttest knowledge

Likelihood to make behavioral changes

\begin{tabular}{l|l|l|l}
\hline Before & 25.17 & 28 & 0.537 \\
\hline After & 33.83 & 35 & 0.177 \\
\hline \multicolumn{5}{|l}{ Wilcoxon signed ranks } \\
\hline$p$ value (within) & 0.027 & 0.068 & \\
\hline
\end{tabular}

\begin{tabular}{l}
\hline Pretest-posttest likelihood to make changes \\
\begin{tabular}{l|c|c|c}
\hline Satisfaction with delivery method \\
\hline After & 30.17 & 34.2 & 0.340 \\
\hline
\end{tabular}
\end{tabular}

on knowledge, likelihood of making behavioral changes, and in being a satisfactory mode of education.

In assessing whether there were significant differences within groups in pre- and postintervention results in knowledge and likelihood of making changes to decrease vascular risk factors, the Wilcoxon signed test was utilized (Table 2). There were significant improvements $(p \leq 0.05)$ in the pre- and post-knowledge score in both groups. The in-person group improved in knowledge by 3.8 points or $21.1 \%$. The telehealth group increased by 5.5 points or $30.5 \%$ in knowledge. This significant improvement in knowledge for both groups suggests that the telehealth and the in-person education were effective at increasing knowledge of stroke.

Both groups increased in their stated likelihood of taking action to decrease their vascular risks. There were significant differences $(p \leq 0.5)$ in the pre- to postlikelihood scores of the telehealth group. This indicates a difference from pretest to posttest likelihood by 8.6 points or a $24.6 \%$ increase in likelihood of taking preventive actions for the telehealth group. The pre- to postlikelihood scores within the in-person group were not found to be significant ( $p \geq 0.05$ ). However, the likelihood of taking action did improve by 7 points or a $20 \%$ increase in score. These results suggest that the in-person and the telehealth programs were effective in improving knowledge and in increasing likelihood of taking behavioral actions to decrease vascular risk factors, even though the increase was not significant for the in-person group. 


\section{TELEHEALTH STROKE EDUCATION}

\section{Discussion}

This study was performed to determine whether there was a significant difference in the satisfaction, knowledge, and likelihood of taking preventive action against stroke with adults receiving inperson versus telehealth delivered stroke prevention education. It was determined that there was no significant difference between the two groups in the areas of satisfaction and knowledge after the education. This suggests that in-person and telehealth stroke education programs are equally satisfying to the participants and can result in similar knowledge acquisition. The data also suggested that the telehealth delivered education was effective in increasing likelihood of making behavioral changes to decrease vascular risk factors. This suggests that the telehealth program may have been more effective in increasing the participant's motivation in modifying behaviors to decrease vascular risk factors. Both groups did increase in their likelihood of making changes thus suggesting that the level of significance for the in-person group in likelihood of changing their behaviors may have been the result of a small sample size.

The findings of this study show promise in providing educational avenues for clinicians and educators caring those at risk for stroke. The results of this study suggest that telehealth stroke education is both feasible and effective for the rural elderly. Those in remote rural areas often do not have ready access to the healthcare expertise found in many urban areas. Through telehealth, many of these services can be made available to these remote populations. This in turn has the potential to improve access and health outcomes. Through telehealth educational programs, rural patients could be better informed and thus able to incorporate prevention behaviors into their lives. The benefits to the subjects in this study included access to stroke education, high satisfaction, and cost savings since there was no burden of travel and transport. For the provider, benefits include increased efficiency for clinician educators, and retaining resources locally since subjects remained in their own community for the educational session. This study suggests further applicability of telehealth in stroke care, as integrating stroke prevention education is an important aspect in the realm of stroke management.

\section{LIMITATIONS}

Although 19 subjects consented to be in the study, only 11 were present for the stroke education sessions. The small number of participants resulted in the study being underpowered and unable to show greater applicability. Future programs should be given on several different days in order to optimize the participation of those who may not be able to attend due to health issues or competing responsibilities. Another limitation is that the short time frame of the study did not allow for follow-up of the subjects after the initial education session. Length of retainment of knowledge and actual changes in behaviors to decrease risk as influenced by the stroke education remain unknown. It would be more informative to assess the participants several months after the program to determine whether they had actually changed their behaviors and retained the knowledge they had gained.

\section{Conclusions}

Interventions aimed at educating individuals about stroke risk are needed to decrease the incidence of stroke. This study suggested that stroke education via telehealth is readily accepted by elderly rural adults and effective at improving knowledge of stroke and stroke risk factors as well as increasing the likelihood to making changes to decrease vascular risk factors. This study offers the possibility of an expanded role of telehealth in educating those at risk for stroke who live in remote areas. Telehealth coupled with stroke prevention education is an effective combination of clinical practice and technology. Telehealth stroke prevention education is an important adjunct in the effort to provide excellence in stroke care and decrease incidence of stroke in all populations regardless of geographic location.

\section{Acknowledgments}

This research was made possible by collaboration between the University of Virginia Department of Telemedicine, Charlottesville, Virginia; the PACE Center at Big Stone Gap, Virginia; and Old Dominion University Graduate School of Nursing, Norfolk, Virginia.

\section{Disclosure Statement}

No competing financial interests exist.

\section{REFERENCES}

1. Joubert J, Prentice LF, Moulin T, Liaw ST, Joubert LB, DeLitt $P$, et al. Stroke in rural areas and small communities. Stroke 2008;39:1920-1928.

2. Roger VL, Go AS, Lloyd-Jones DM, Adams RJ, Berry JD, Brown TM, et al. AHA statistical update: Heart disease and stroke statistics-2011 update. A report from the American Heart Association. 2010;123:e18-e209. Available at http:/| circ.ahajournals.org/cgi/content/full/123/4/e18 (last accessed May 15, 2011).

3. Saposnik G, Black SE, Hakim A, Fang J, Tu JV, Kapral MK. Age disparities in stroke quality of care and delivery of health services. Stroke 2009;40:3328-3335.

4. Joubert J, Barton $D_{1}$ Cumming $M$, McLean $A_{1}$ Joubert $L$, Bell $C_{\text {, }}$ et al. Integrated care improves risk-factor modification after stroke: Initial results of the integrated care for the reduction of secondary stroke model. J Neurol Neurosurg Psychiatry 2009;80:279-284.

5. Casey $M$, Call $K$, Klinger J. Are rural residents less likely to obtain recommended preventative health care services? Am J Prev Med 2001;2:182-188.

6. Becker KJ, Fruin MS, Gooding TD, Tirschwell DL, Love PJ, Mankowski TM. Community based education improves stroke knowledge. Cerebrovasc Dis [Internet] 2001;11:34-43. doi: 10.1159/000047609 (last accessed April 5, 2010).

7. Ellis $\mathrm{G}$, Rodger J, McAlpine $\mathrm{C}$, Langhorne $\mathrm{P}$. The impact of stroke nurse specialist input on risk factor modification: A randomized controlled trial. Age Ageing 2005;34:389-392.

8. Eriksson S, Kaati G, Bygren LO. Personal resources, motives and patient education leading to changes in cardiovascular risk factors. Patient Educ Couns [Internet] 1998;34:159-168. Available at www.ncbi.nlm.nih.gov/pubmed/ 9731175 (last accessed February 1, 2011).

9. Fang XH, Kronmal RA, Li SC, Longstreth WT, Cheng XM, Wang W, et al. Prevention of stroke in urban China-A community based intervention trial. Stroke 1999;30:495-450.

10. Allisona R, Evans PH, Kilbridec C, Campbell JL. Secondary prevention of stroke: Using the experiences of patients and carers to inform the development of an educational resource. Fam Pract 2008;2:355-361. 


\section{SCHWEICKERT ET AL.}

11. Moulin T, Audebert HJ. Telestroke in stroke survivors. Cerebrovas Dis [Internet] 2009;27:28-35. doi:10.1159/000213056 (last accessed March 23, 2010).

12. Smith J, Forster A, Young J. A randomized trial to evaluate an education program for patients and carers after stroke. Clin Rehabil [Internet] 2004;18: 726-736. doi: 101191/0269215504cr790oa (last accessed May 2, 2010).

13. Meyer BC, Raman R, Hemmen MD, Obler R, Zivin JA, Rao R, et al. Efficacy of site independent telemedicine in the stroke doc trial: A randomized, blinded, prospective study. Lancet Neurol 2008;7:787-795.

14. Schwab S, Vatankhah B, Kukla C. Long-term outcome after thrombolysis in telemedical stroke care. Neurology 2007;69:898-903.

15. Schwamm L, Holloway RG, Amarenco P, Audebert HJ, Bakas T, Chumbler NR, et al. A review of the evidence for the use of telemedicine within stroke systems of care: A scientific statement from the American Heart Association/American Stroke Association. Stroke 2009;40:2616-2634.

16. Lezzoni L, Killeen MB, O'Day BL. Rural residents with disabilities confront substantial barriers to obtaining primary care. Health Serv Res [Internet] 2006;41:1258-1275. doi: 10.111/j.1475-6773:2006.00534.x (last accessed January 1, 2010)

17. Winters JM, Winters DL. Videoconferencing and telehealth technologies can provide a reliable approach to remote assessment and teaching without compromising quality. J Cardiovasc Nurs 2007;22:51-57.

18. Izequierdo RE, Knudson PE, Meyer S, Kearns J, Ploutz-Snyder R, Weinstock RS. A comparison of diabetes education administered through telemedicine versus in person. Diabetes Care [Internet] 2002;26:1002-1007. Available at http:// care.diabetesjournals.org/cgi/pmidlookup?view=longHYPERLINK "http:// care.diabetesjournals.org/cgi/pmidlookup?view=long\&" \&pmid=12663564 (last accessed January 2, 2010)

19. Timmerberg BD, Wurst J, Patterson J, Spaulding RJ, Belz NE. Feasibility of using videoconferencing to provide diabetes education: A pilot study. J TeleMed Telecare [Internet] 2009;15:95-97. Available at www.ncbi.nl.nih.gov/pubmed/ 19246610 (last accessed January 27, 2010).

20. Chan WM, Woo J, Lau WW, Lee D. A community model for care of elderly people with diabetes with telemedicine. Appl Nurs Res [Internet] 2005;18:77-81. Available at www.ncbi.nl.nih.gov/pubmed/15991104 (last accessed January 4, 2010).

21. Balamurugan A, Hall-Barrow J, Blevins MA, Brech D, Phillips M, Holley E, Bittle K. A pilot study of diabetes education via telemedicine in a rural underserved community-opportunities and challenges. Diabetes Educ [Internet] 2008;3: 21-26. Available at http://tde.sagepub.com/cgi/contents/full/35/1/147 (last accessed February 3, 2010).

22. Verhoeven F, Van Gemert-Pijnen L, Dijkstra K, Nijland N, Seydel E, Steehouder $\mathrm{M}$. The contribution of teleconsultation and videoconferencing to diabetes care:
A systematic literature review. J Med Internet Res [Internet] 2007;9:37-56. doi: 10.2196/jmir.9.5.e37 (last accessed January 4, 2010).

23. Centers for Disease Control and Prevention. Chronic Disease Health Promotion. 2009 [Internet]. Available at www.cdc.gov/chronicdisease/healthequity/ index.htm (last accessed February 24, 2010).

24. Picker Institute. Patient-centered care 2015: Scenarios, vision, goals \& next steps. Picker Institute Report [Internet] 2004. Available at http:// 174.120.202.186/ pickerin/wp-content/uploads/2010/06/PCC-2015.pdf (last accessed January 9, 2010).

25. U.S. Department of Health and Human Services. Healthy People 2020 [Internet] 2010. Available at www.healthypeople.gov/2020/default.aspx (last accessed March 30, 2011).

26. Faxon DP, Schwamm LH, Pasternak RC, Paterson ED, McHeil BJ, Bufalino V. Improving quality of care through disease management: Principles and recommendations from the American Heart Association's expert panel on disease management. Circulation [Internet] 2004;109:2651-2654. Available at http://stroke.ahajournals.org/cgi/pmidlookup?view=longHYPERLINK "http:// stroke.ahajournals.org/cgi/pmidlookup?view=long\&pmid=10066842" \&HYPERLIN "http://stroke.ahajournals.org/cgi/pmidlookup?view= long\&pmid = 10066842"pmid=10066842 (last accessed March 26, 2010).

27. Goldstein LB, Bushnell CD, Adams RJ, Appel U, Braun LT, Chaturvedi S, et al. Guidelines for the primary prevention of stroke. A guideline for healthcare professionals from the American Heart Association/American Stroke association. Stroke 2011;42:517-584.

Address correspondence to: Patricia A. Schweickert, D.N.P., F.N.P.-B.C.

Department of Radiology

University of Virginia

Health Sciences Center

1215 Lee St.

Charlottesville 22908

Virginia

E-mail: pas9c@virginia.edu

Received: April 24, 2011

Accepted: May 14, 2011 